\title{
Analysis of load carrying capacity and destruction mechanism of an intermediate anchorage steel plate for pillar jib crane
}

\author{
Matgorzata Gordziej-Zagórowska ${ }^{1, *}$, and Wojciech Migda ${ }^{1}$ \\ ${ }^{1}$ Gdańsk University of Technology, Faculty of Civil and Environmental Engineering, \\ ul. Narutowicza 11/12, 80-233 Gdańsk, Poland
}

\begin{abstract}
Pillar jib cranes are often mounted to existing floors with the use of an intermediate anchorage steel plate instead of using independent foundations. The process of designing such an intermediate plate for a pillar jib crane and a destruction pattern for plates of insufficient thickness are presented in this article. The required steps of the designing process are introduced and also the required level of detail for the numerical analysis. The aim of this paper is to provide a secure and safe approach to the design of such intermediate anchorage plates.
\end{abstract}

\section{Introduction}

Pillar jib cranes find their way to all kind of different production facilities very often after the design and erection process is finished, therefore a way of secure mounting to existing floors has to be provided. The simplest and easiest way for this is the use of a so called intermediate steel anchorage plate (Fig. 1). The basic design as for the used shape is simple, a plate can be either circular or square (sometimes a rectangular shape might be useful). The size of the designed plate can be estimated by the maximum allowed tension force in the anchor bolts. Standards for steel design [1], [2] provide only basic rules for the design of such an intermediate plate and the design of (planar) dimensions and the thickness of the plate require additional calculations. For the calculations of the load carrying capacity of an intermediate steel plate the use of a FEM (finite element method) model is very helpful, several aspects, beside the dimension and thickness and material strength of the steel plate, need to been taken into consideration. These aspects are: stiffness of the floor the baseplate will be anchored to, the concrete strength of the floor, the stiffness of the soil underneath the floor, the placement and diameter of the anchor bolts and the tensile strength.

While the initial estimation of the proper placement of the anchors and the dimension of the plate is not very difficult due to existing information for calculations [2], [3], [5] the whole design process requires proper understanding of how the different parameters interact with each other and how they influence the final result - the correct dimensions of the plate.

\footnotetext{
${ }^{*}$ Corresponding author: malgor@pg.edu.pl
} 


\section{Steps of the design process}

The design process of an intermediate anchorage steel plate for a jib pillar crane can be divided into the following steps:

- defining of the basic known parameters: design forces for the crane, dimension of the pillar base plate and placement of the bolts (fasteners between base plate and intermediate plate), thickness of the floor plate (slab), material properties of the floor and the soil parameters for the overall floor stiffness,

- initial definition of the intermediate plate planar dimensions and anchor placement based on the floor thickness,

- definition of the FEM model and the proper application of the supports and acting forces,

- analysis of the results.
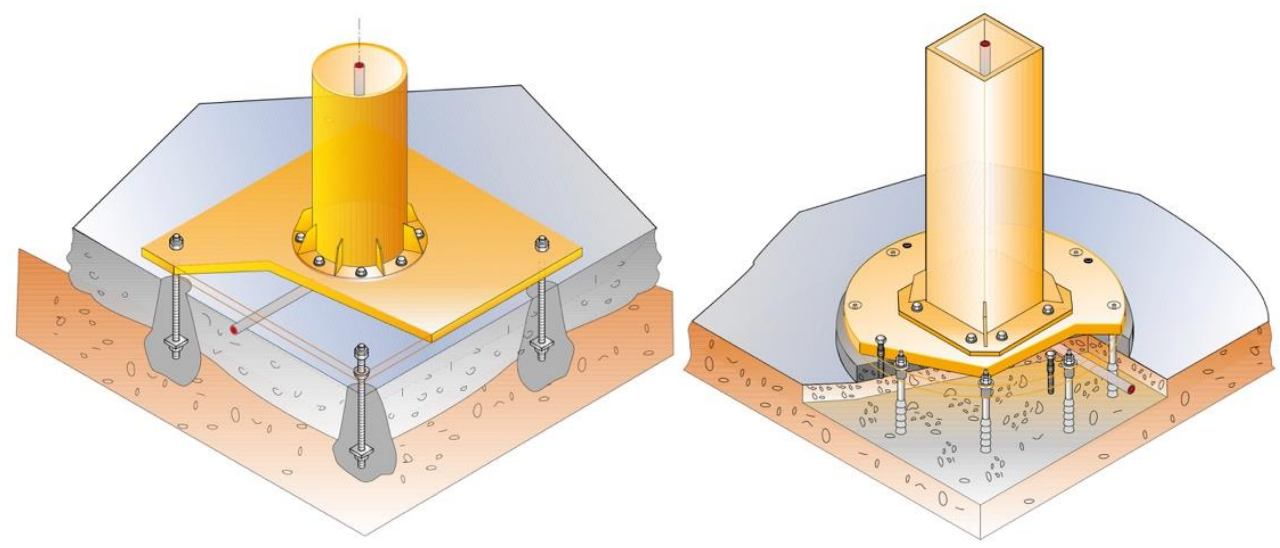

Fig. 1. Square and round intermediate anchorage plate [3].

\section{Definition of the basic parameters}

The basic parameters required for the proper design start with the design working loads and the geometry of the base plate anchorage for the chosen pillar crane. For the example used in this paper a jib pillar crane model LS 235 from ABUS with a span of $5000 \mathrm{~mm}$ and a work load of $1000 \mathrm{~kg}$ was used, as presented in Fig. 2. The characteristic loads are: axial load (vertical force at base plate) $\mathrm{N}_{\mathrm{F}}=17.7 \mathrm{kN}$ and overturning moment (OTM) $\mathrm{M}_{\mathrm{F}}=56.7 \mathrm{kNm}$, these values have been used as these have been provided by the producer for the calculations of a intermediate plate.

In the next step the thickness of the concrete floor has to be determined, for this analysis a thickness of $300 \mathrm{~mm}$ was assumed. Further more it was assumed that the concrete is of grade C20/16. The effective maximum usable length for chemical (adhesive) anchoring bolts is less then the floor thickness, because while drilling through the whole floor at the bottom of the floor a cracking can occur as shown in Fig. 4. It is recommender to reduce the drill depth by $50 \mathrm{~mm}$ to avoid the cracking, it is also recommended to drill the last bits without hammering.

The following step requires few initial assumptions and simplified calculations as a starting point - these are the diameter of the intermediate plate (in case of a square plate the length of the sides should be equal to the diameter of a circular plate) and the distance between the anchors. 


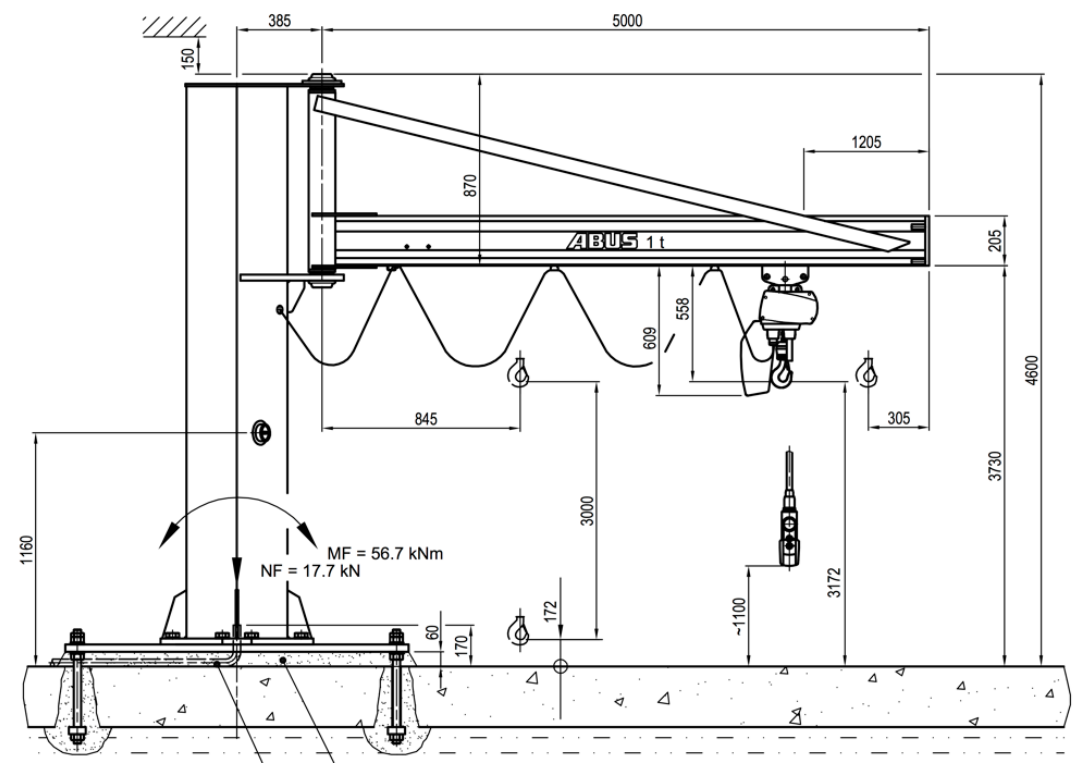

Fig. 2. General dimensions of the jib pillar crane.
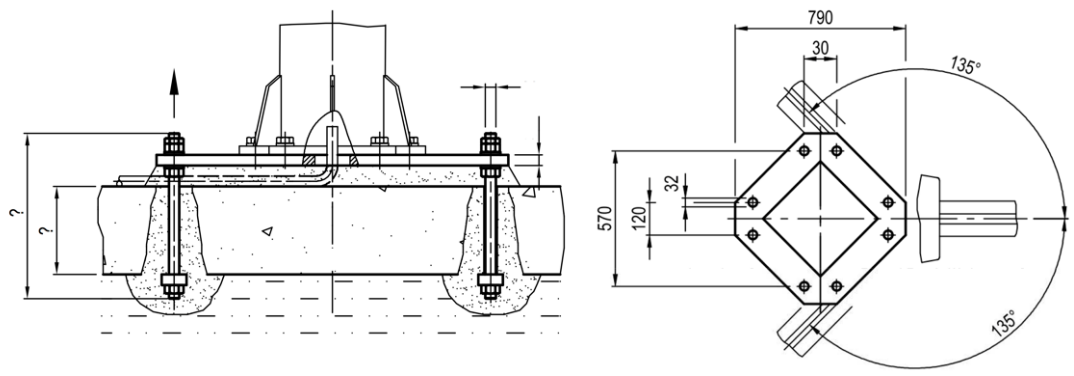

Fig. 3. Dimensions of the base plate and the hole for the base plate bolts.

The distance between the anchors can be calculated based on the number of anchors and basis of the length of the anchors assuming that the concrete cone of force dispersion around every anchor - assuming that chemical anchors provide higher tensile (anchorage) force than the concrete cone of force dispersion - has an angle of spread of $33.7^{\circ}$ (according to [4] $-8.10 .3(5)$ ), which is not only a safer approach (by reducing the size of the cone) then using the typical angle for the cone of spread for concrete that is around $55^{\circ}$ but seems more accurate since these anchors are pre-tensioned (just as tendons, for which [4] suggests $33.7^{\circ}$ ) before the workload of the crane and correlating forces occur.

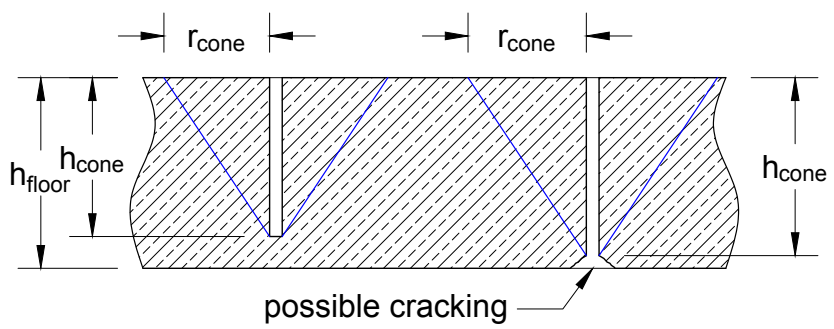

Fig. 4. Dimensions for the estimation of the concrete breakout cone. 
Usually the use of 12 anchors as total provides a good distribution of forces leaving $30^{\circ}$ between anchors. The distance between anchors should be calculated so that the cones of spread around the anchors don't interact. With this in mind the distance between the anchors $d_{\text {cone }}$ should be not less as presented in equation (1):

$$
d_{\text {cone }}=2 * r_{\text {cone }}=2 * h_{\text {cone }} * \tan 33.7
$$

where:

$r_{\text {cone }} \quad$ radius of the cone, $r_{\text {cone }}=167 \mathrm{~mm}$,

$h_{\text {cone }}$ effective length of the anchor bolt - a safe assumption is $h_{\text {cone }}=h_{\text {floor }}-50 \mathrm{~mm}$,

$h_{\text {floor }}$ thickness of the concrete floor.

\section{Initial calculations for the intermediate plate dimensions}

Based on the distance between the anchors, the diameter $D_{\text {plate }}$ of the intermediate plate can be calculated (2). A larger diameter of the intermediate plate will result in lower forces in the anchor bolts and also in lower compression force on top of the floor.

$$
D_{\text {plate }} \cong \frac{n * d_{\text {cone }}}{\pi}+2 * b
$$

where:

n number of anchors - for this study 12 anchor bolts have been used,

$b$ distance from centre of the anchor axis to the edge of the intermediate plate $-50 \mathrm{~mm}$ is usually a good value.

Using the above equations and assumptions ( $\left.h_{\text {cone }}=250 \mathrm{~mm}, n=12, b=50 \mathrm{~mm}\right)$ the calculated diameter of the intermediate plate is $1373 \mathrm{~mm}$, for the further calculations a diameter of $1400 \mathrm{~mm}$ was used.

At this stage it is possible to check if the overturning moment of the crane, as a pair of forces will generate a force in the most exposed anchor bolt that is smaller than the resistance of the cone of force of dispersion $\left(F_{\text {cone }}\right)$, for this the area of the cone $\left(A_{\text {cone }}\right)$ has to be calculated and the total force of dispersion (3).

$$
F_{\text {cone }}=A_{\text {cone }} * \tau_{R d, C 20 / 16}=\pi * r_{\text {cone }} * h_{\text {cone }} * \tau_{R d, C 20 / 16}
$$

where:

Acone $\quad$ conical surface, $A_{\text {cone }}=1311 \mathrm{~cm}^{2}$,

$\tau_{R d, C 20 / 16}$ shear resistance of concrete (according to [6]), $\tau_{R d, C 20 / 16}=0.022 \mathrm{kN} / \mathrm{cm}^{2}$,

Fcone force of dispersion of the concrete cone around the anchor bolt, $F_{\text {cone }}=28.8 \mathrm{kN}$.

With the force of dispersion calculated the class and diameter of the anchor bolt can be determined, for this example anchors of class 5.6 [2] and M20 have been used.

For the numerical analysis yet another parameter is required - the stiffness of the floor $k$. The stiffness can be either experimentally determined, which is the most preferred solution - for this a load should be placed at the location of the designed intermediate plate and the deflection of the floor under the load should be measured. If this is not possible the stiffness of the floor should be calculated (using computer software like Autodesk Robot Structural Analysis) or estimated, for instance using the procedure presented in [7]. A value of $k=0,03 \mathrm{MPa} / \mathrm{mm}=30000 \mathrm{kN} / \mathrm{m}^{3}$ can be used for industrial floors with a thickness of $300 \mathrm{~mm}$ (including the underlying soil), this means that a force creating a pressure of 0,03 $\mathrm{MPa}$ will generate a displacement of the floor that is equal to $1 \mathrm{~mm}$. By implementing the floor and soil stiffness in such a way takes the soil and floor in this calculations into 
account without the need of modelling them explicit. It is yet recommended to measure the stiffness of the floor if possible, because it will provide more accurate results.

\section{Numerical model and analysis}

With all the initial parameters established the numerical FEM model was created using the program RFEM by Dlubal. The following parameters have been incorporated:

- diameter of the intermediate plate: $1400 \mathrm{~mm}$,

- radius of the axis of the anchor bolts: $650 \mathrm{~mm}(=1400 / 2-50)$,

- node supports for anchor bolts, supporting only displacements ux, uy and uz only against tension, compression is handled by surface support,

- surface support with a stiffness of $30000 \mathrm{kN} / \mathrm{m}^{3}$, and providing only support against compression,

- load transfer from crane pillar base plate to intermediate plate was handled with nodal forces located at the places of bolts (as shown in Fig. 3) - 8 nodes,

- the overturning moment was implemented by replacing a moment with a pair of forces (as shown in Fig. 6),

- the vertical force was equally applied to all 8 nodes (as shown in Fig. 6),

- two different cases have been analysed with different safety factors: one to estimate the forces in the anchor bolts and one for the contact compression for the floor - the load and combination cases are presented in Table 1 and 2,

- different thicknesses of the intermediate plate have been used, starting at $50 \mathrm{~mm}$ and reducing the thickness by $5 \mathrm{~mm}$ up to a thickness of $10 \mathrm{~mm}$,

- as the material of the intermediate plate steel of grade S355 was used,

- the size of the FE was set to $1 \mathrm{~cm}$ and the calculation method that was used, was a postcritical analysis.

Table 1. Load cases used in the numerical analysis.

\begin{tabular}{|c|c|}
\hline Load case & Type of load \\
\hline LC 1 & dead load \\
\hline LC 2 & vertical force \\
\hline LC 3 & overturning moment \\
\hline
\end{tabular}

Table 2. Load combinations with safety factors used in the numerical analysis.

\begin{tabular}{|c|c|}
\hline $\begin{array}{c}\text { Load } \\
\text { combination }\end{array}$ & Loads and safety multipliers \\
\hline CO 1 & $0.9 * \mathrm{LC} 1+0.9 * \mathrm{LC} 2+1.5 * \mathrm{LC} 3$ \\
\hline CO 2 & $1.35 * \mathrm{LC} 1+1.5 * \mathrm{LC} 2+1.5 * \mathrm{LC} 3$ \\
\hline
\end{tabular}

In Fig. 5 and Fig. 6 the FEM model is presented showing the node supports (light blue) and surface supports (red), also showing the nodal forces representing the vertical force $\mathrm{N}_{\mathrm{F}}$ and the overturning moment $\mathrm{M}_{\mathrm{F}}$.

\section{Evaluation of the results}

The results of the numerical analysis have been presented Table 3. For comparison the maximum equivalent von Mises stress that occurred in the intermediate plate, the maximum force (in form of $\mathrm{Pz}$ reaction of the nodal supports) in the bolts and the maximum contact stress (in form of surface support) have been taken into consideration. The comparison was carried out for the different thickness of the intermediate steel plate, starting at $50 \mathrm{~mm}$ 
finishing at $10 \mathrm{~mm}$ with a step of $5 \mathrm{~mm}$. As can be seen from the results, not only did the values of the examined parameters alter but also the distribution of stress and deformation of the intermediate plate. In Fig. 7 to Fig 9. the overall deformation of the plate, the contact stress and the equivalent von Mises stress are presented, from load case 1 (CO1) for the thinnest and the thickest plate analysed.

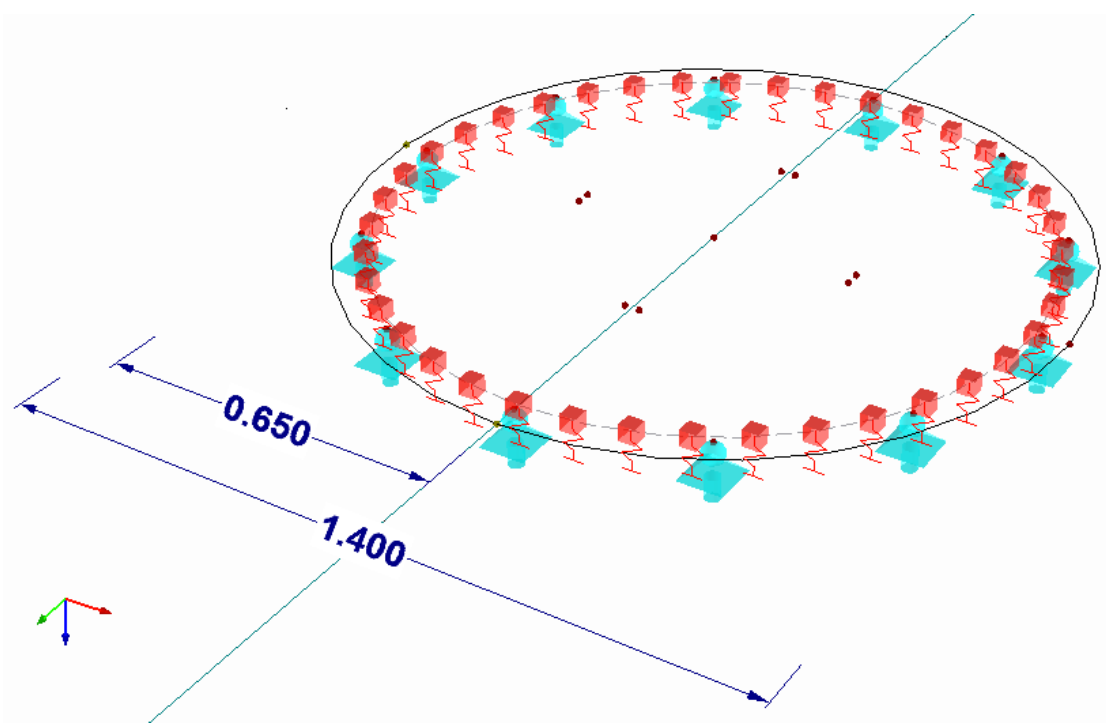

Fig. 5. FEM model of the base plate and the holes for the base plate bolts and supports.
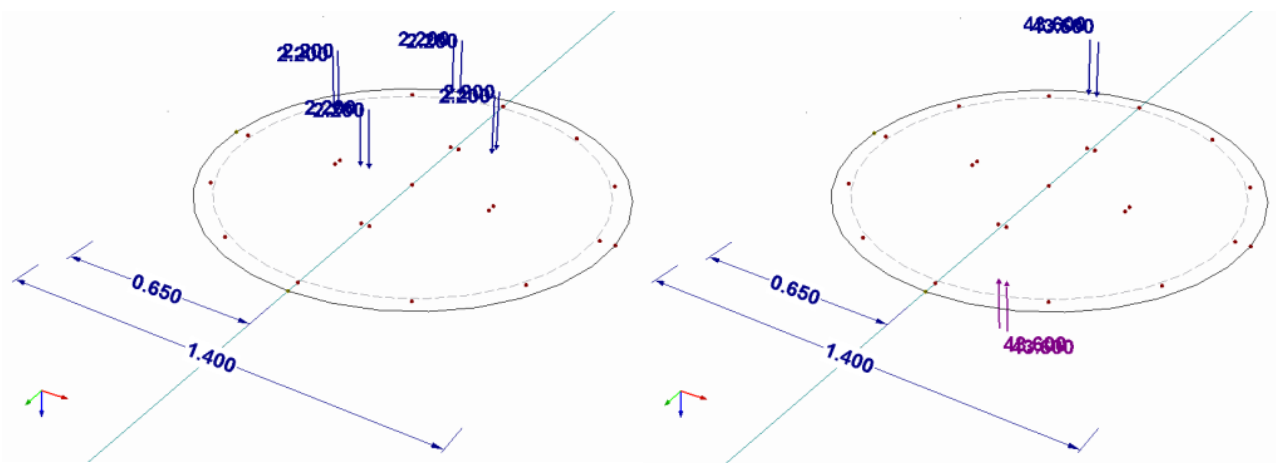

Fig. 6. Placement of the vertical forces $\left(\mathrm{N}_{\mathrm{F}} / 8 \cong .2 \mathrm{kN}\right)$ and overturning moment $\left(\mathrm{M}_{\mathrm{F}} / 2 * 0.57 \cong 9.7 \mathrm{kN}\right)$.
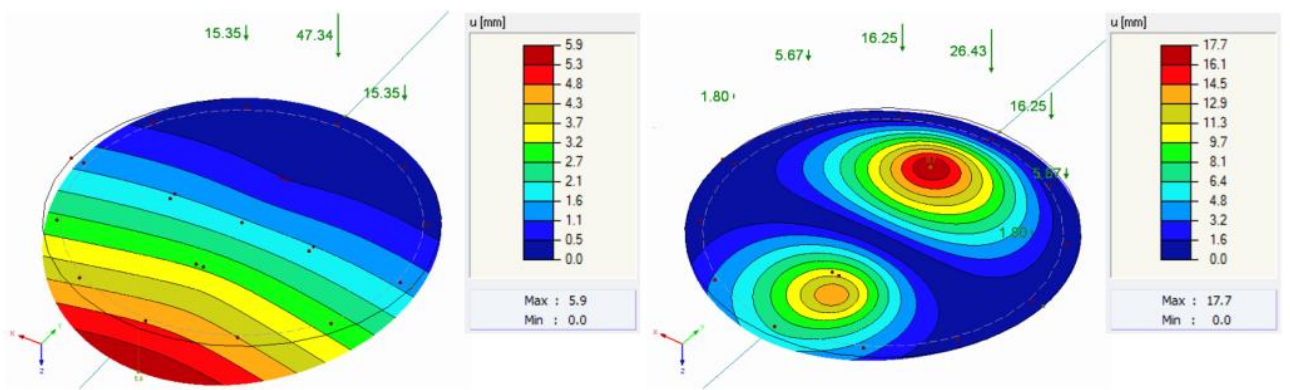

Fig. 7. Global deformation of the intermediate plate for $50 \mathrm{~mm}$ and $10 \mathrm{~mm}$ thickness $(50 \mathrm{~mm}$ plate shown on the left). 

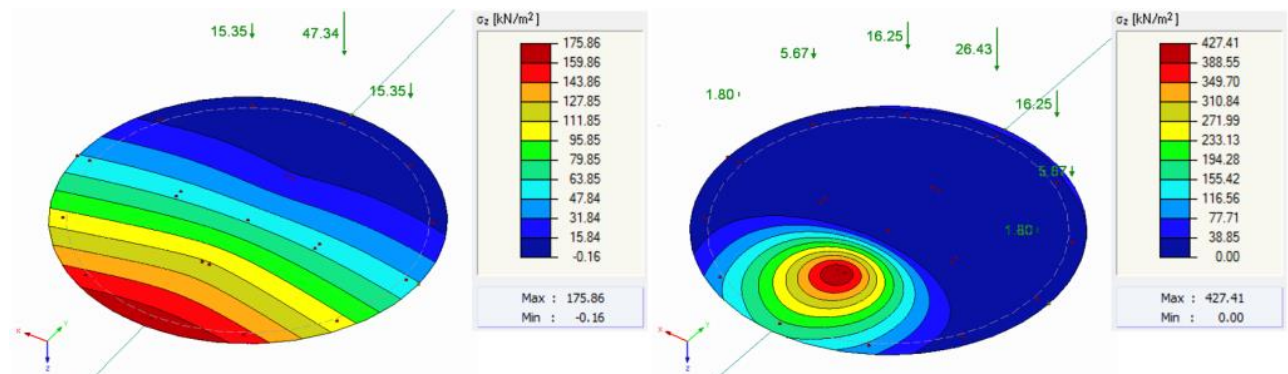

Fig. 8. Contact stress of the intermediate plate for $50 \mathrm{~mm}$ and $10 \mathrm{~mm}$ thickness $(50 \mathrm{~mm}$ plate shown on the left).
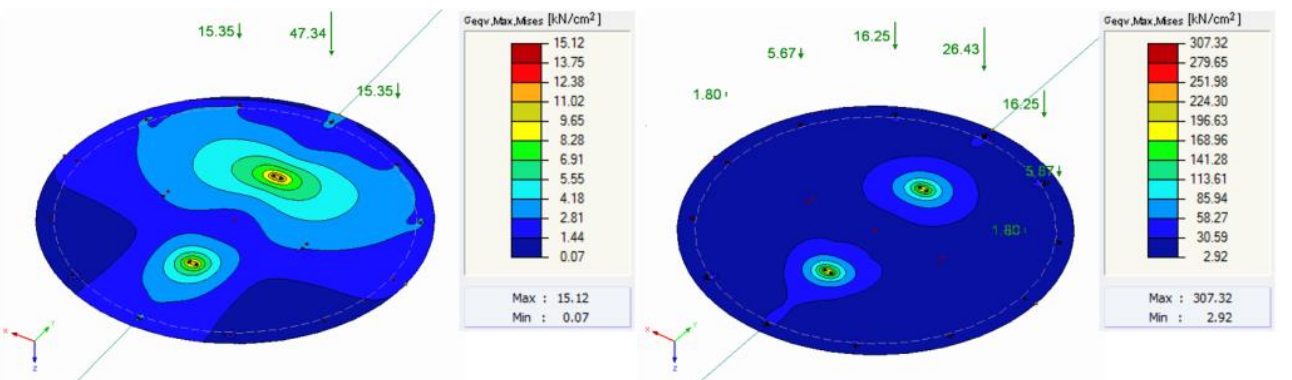

Fig. 9. Equivalent von Mises stress of the intermediate plate for $50 \mathrm{~mm}$ and $10 \mathrm{~mm}$ thickness $(50 \mathrm{~mm}$ plate shown on the left).

Table 3. Comparison of the maximum results for contact stress, equivalent von Mises stress and axial force in anchor bolts for different intermediate plate thickness from the numerical analysis for both load combinations.

\begin{tabular}{|c|c|c|c|c|c|c|}
\hline \multirow{2}{*}{$\begin{array}{c}\begin{array}{c}\text { Load } \\
\text { combination }\end{array} \\
\text { Plate } \\
\text { thickness } \\
{[\mathrm{mm}]}\end{array}$} & \multicolumn{3}{|c|}{ CO 1} & \multicolumn{3}{|c|}{$\mathrm{CO} 2$} \\
\hline & $\begin{array}{l}\sigma_{\text {eqv,max }} \\
{\left[\mathbf{k N / \mathbf { c m } ^ { 2 } ]}\right.}\end{array}$ & $\begin{array}{c}\mathbf{P}_{\mathbf{z}, \max } \\
{[\mathrm{kN}]}\end{array}$ & $\underset{\left[\mathrm{kN} / \mathbf{m}^{2}\right]}{\sigma_{\text {contact, }} \text { max }}$ & $\begin{array}{l}\sigma_{\text {eqvi }} \text { max } \\
{\left[\mathbf{k N} / \mathbf{c m}^{2}\right]}\end{array}$ & $\begin{array}{c}\mathbf{P}_{\mathbf{z}, \max } \\
{[\mathrm{kN}]}\end{array}$ & $\underset{\left[\mathrm{kN} / \mathrm{m}^{2}\right]}{\sigma_{\text {contact, max }}}$ \\
\hline 50 & 15.12 & 47.34 & 175.86 & 14.80 & 50.69 & 187.85 \\
\hline 45 & 18.46 & 37.52 & 182.46 & 18.05 & 39.93 & 193.80 \\
\hline 40 & 23.12 & 29.76 & 190.58 & 22.61 & 31.36 & 201.19 \\
\hline 35 & 29.92 & 24.24 & 200.43 & 29.30 & 25.16 & 210.01 \\
\hline 30 & 40.44 & 23.73 & 210.42 & 39.57 & 22.67 & 219.18 \\
\hline 25 & 58.01 & 24.30 & 217.84 & 56.71 & 23.32 & 224.81 \\
\hline 20 & 90.03 & 24.77 & 220.22 & 88.09 & 23.83 & 231.36 \\
\hline 15 & 151.29 & 25.47 & 292.50 & 150.79 & 24.58 & 307.39 \\
\hline 10 & 307.32 & 26.43 & 427.41 & 297.38 & 25.56 & 444.38 \\
\hline
\end{tabular}

As can be seen from the presented results the proper thickness of the intermediate plate is very important, because the use of a very thick plate results in increased force in the bolts, whereas a too thin plate results in a very large deformation and equivalent von Mises stress that would result in destruction of the intermediate plate and also increase in contact 
stress that could lead to local destruction of the concrete floor. The optimum thickness for the plate is $30 \mathrm{~mm}$ for the presented case, that is where the forces in the anchoring bolts are the lowest. The results in the bolt (first decreasing and then increasing, as shown in Fig. 10) indicate that a state of best (equal) force distribution is achieved by a plate of $30 \mathrm{~mm}$ thickness.

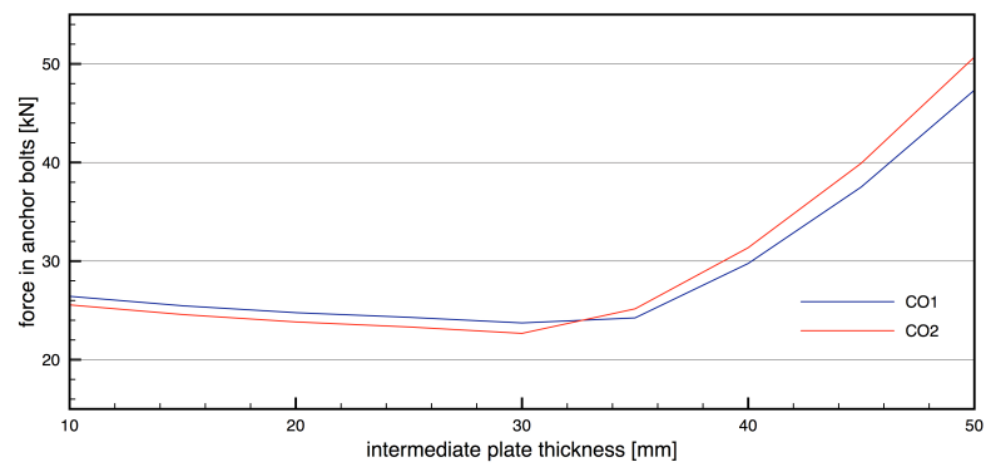

Fig. 10. Force in anchor bolts for both load cases in relation to the intermediate plate thickness.

\section{Conclusions}

A rather simple task as the design of an intermediate plate for a jib pillar crane requires a good understanding of the interaction of all the parameters that are involved in the design process of such a plate. This paper should give a fair overview of how these parameters influence one another and what aspects need to be considered. As can be seen from the analysis of the results, the most critical role plays the thickness of the intermediate plate. Furthermore it can be seen that the required FEM model for the calculations is very simple but delivers all needed information in order to verify the assumed geometrical and material properties of the designed plate.

\section{References}

1. EN 1993-1-5, Eurocode 3: Design of steel structures - Part 1-5: General rules - Plated structural elements, Eur. Comm. Stand. (2006)

2. EN 1993-1-8, Eurocode 3: Design of steel structures - Part 1-8: Design of joints, Eur. Comm. Stand. (2005)

3. ABUS Kransysteme GmbH, AN 12283 03.17, www.abuscranes.com

4. EN 1992-1-1, „Eurocode 2: Design of concrete structures - Part 1-1 : General rules and rules for buildings", Eur. Comm. Stand. (2004)

5. Model Code 1990: Design Code, CEB-FIB, Thomas Telford Services Ltd., Lausanne ISBN 0727716964 (1993)

6. PN-B-03264:2002. Konstrukcje betonowe, żelbetowe i sprężone. Obliczenia statyczne i projektowanie

7. W. Ryżyński, B. Karczewski, Wyznaczanie parametrów obliczeniowych podłoża warstwowego pod posadzką przemysłową. Nowoczesne Hale, 5, 14, 34-38 (2014) 